\title{
Fertility of fresh and frozen sex-sorted semen in dairy cows and heifers in seasonal-calving pasture-based herds
}

\author{
C. Maicas,,${ }^{1,2}$ I. A. Hutchinson, ${ }^{1}$ J. Kenneally, ${ }^{1}$ J. Grant, ${ }^{3}$ A. R. Cromie, ${ }^{4}$ P. Lonergan, ${ }^{2}$ and S. T. Butler ${ }^{1 *}$ \\ ${ }^{1}$ Animal and Grassland Research and Innovation Centre, Teagasc, Moorepark, Fermoy, Co. Cork, Ireland P61 P302 \\ ${ }^{2}$ School of Agriculture and Food Science, University College Dublin, Belfield, Dublin 4, Ireland D04 N2E5 \\ ${ }^{3}$ Research Operations Group, Teagasc, Ashtown, Dublin 15, Ireland D15 DY05 \\ ${ }^{4}$ Irish Cattle Breeding Federation, Highfield House, Shinagh, Bandon, Co. Cork, Ireland P72 X050
}

\section{ABSTRACT}

Our objective in this study was to evaluate the reproductive performance of dairy heifers and cows inseminated with fresh or frozen sex-sorted semen (SS) in seasonal-calving pasture-based dairy herds. Ejaculates of 10 Holstein-Friesian bulls were split and processed to provide (1) fresh conventional semen at $3 \times 10^{6}$ sperm per straw $(\mathrm{CONV})$; (2) fresh SS at $1 \times 10^{6}$ sperm per straw (SS-1M); (3) fresh SS semen at $2 \times 10^{6}$ sperm per straw (SS-2M); and (4) frozen SS at $2 \times 10^{6}$ sperm per straw (SS-FRZ). Generalized linear mixed models were used to evaluate the effect of semen treatment and other explanatory variables on pregnancy per artificial insemination $(\mathrm{P} / \mathrm{AI})$ in heifers $(\mathrm{n}=3,214)$ and lactating cows $(\mathrm{n}=5,457)$. In heifers, $\mathrm{P} / \mathrm{AI}$ was greater for inseminations with CONV $(60.9 \%)$ than with SS-FRZ $(52.8 \%)$ but did not differ from SS-1M $(54.2 \%)$ or SS$2 \mathrm{M}(53.5 \%)$. Cows inseminated with CONV had greater $\mathrm{P} / \mathrm{AI}(48.0 \%)$ than cows inseminated with SS, irrespective of treatment (SS-1M, SS-2M, and S-FROZEN; $37.6,38.9$, and $40.6 \%$, respectively). None of the SS treatments differed from each other with regard to $\mathrm{P} /$ $\mathrm{AI}$ in either heifers or cows. The relative performance of SS compared with CONV was also examined [i.e., relative $\mathrm{P} / \mathrm{AI}=(\mathrm{SS} \mathrm{P} / \mathrm{AI}) /(\mathrm{CONV} \mathrm{P} / \mathrm{AI}) \times 100]$. Frozen $\mathrm{SS}$ achieved relative $\mathrm{P} / \mathrm{AI}>84 \%$. Bull affected $\mathrm{P} / \mathrm{AI}$ in both heifers and cows, but no bull by semen treatment interaction was observed. In heifers, P/AI increased with increasing predicted transmitting ability for milk protein percentage. In cows, $\mathrm{P} / \mathrm{AI}$ increased with increasing Economic Breeding Index (EBI) and with days in milk (DIM) at AI but decreased with increasing EBI milk subindex, parity and with $\mathrm{DIM}^{2}$. Cows in parity $\geq 5$ had the lowest $\mathrm{P} / \mathrm{AI}$ and differed from cows in parities 1, 2, or 3. Dispatch-to-AI interval of fresh semen did

Received April 3, 2019.

Accepted June 18, 2019.

*Corresponding author: stephen.butler@teagasc.ie not affect $\mathrm{P} / \mathrm{AI}$ in lactating cows, but a dispatch-to-AI interval by bull interaction was detected whereby $\mathrm{P} / \mathrm{AI}$ was constant for most bulls but increased with greater dispatch-to-AI intervals for 2 bulls. In conclusion, frozen SS achieved greater P/AI relative to conventional semen than was previously reported in lactating cows. Fresh SS did not achieve greater P/AI than frozen SS, regardless of whether the sperm dose per straw was $1 \times$ $10^{6}$ or $2 \times 10^{6}$. A bull effect for all semen treatments, as well as a dispatch-to-AI interval by bull interaction for fresh semen, highlights the importance of using a large team of bulls for breeding management.

Key words: sexed semen, pasture-based system, dairy, fertility

\section{INTRODUCTION}

Use of sex-sorted semen (SS) increases the proportion of female dairy offspring from AI, thereby enabling faster herd expansion; allows surplus breeding females to be sold for profit; facilitates greater usage of beef semen to increase the value of surplus calves sold for beef production; and improves profitability (Murphy et al., 2016). In a seasonal-calving system, use of SS at the start of the breeding period (e.g., first $3 \mathrm{wk}$ ) ensures that all replacement heifers are born at the start of the following calving period. This timing provides advantages for block-rearing of replacement heifers and ensures that all heifers have reached target BW at the time of both first mating and first calving. Additionally, fewer low-priced male dairy calves are born, with a consequent reduction in dystocia (Norman et al., 2010) and calf welfare issues (Hötzel et al., 2014).

Currently, the only commercially available methods to produce semen straws that reliably result in a desired offspring sex bias rely on identification of differences in sperm DNA content (Garner et al., 2013; Faust et al., 2016). The most widely used method for producing flow cytometry-based SS results in an approximately $90 \%$ sex bias (Garner et al., 2013; Vishwanath and Moreno, 
2018). The field fertility of SS is generally impaired, however; pregnancy per AI $(\mathbf{P} / \mathbf{A I})$ with frozen SS at 2 $\times 10^{6}$ sperm per dose was $\leq 81 \%$ of that achieved with conventional semen (i.e., non-SS) (DeJarnette et al., 2009, 2010, 2011; Chebel et al., 2010; Norman et al., 2010; Sales et al., 2011; Healy et al., 2013; Djedović et al., 2016). The relative performance of SS compared with conventional semen is usually reported in studies that have evaluated SS [i.e., relative $\mathrm{P} / \mathrm{AI}=(\mathrm{SS} \mathrm{P} /$ $\mathrm{AI}) /($ conventional semen $\mathrm{P} / \mathrm{AI}) \times 100]$, and the relative $\mathrm{P} / \mathrm{AI}$ is generally similar in cows and heifers. A dose response study with increasing numbers of sperm per straw indicated that the reduced $\mathrm{P} / \mathrm{AI}$ achieved with SS relative to conventional semen were noncompensable (DeJarnette et al., 2011).

Excellent fertility performance is an important driver of farm profitability, particularly in seasonal-calving pasture-based systems (Shalloo et al., 2014), in which the objective is to rapidly establish pregnancy in as many cows as possible to achieve a compact calving pattern during the subsequent spring-calving period. Hence, one of the main barriers to adoption of SS in pasture-based systems is the unsatisfactory $\mathrm{P} / \mathrm{AI}$ achieved.

Use of liquid (fresh, nonfrozen) semen has traditionally been restricted to countries with seasonal-calving pasture-based systems in which inseminations are confined to a short breeding season, leading to a concentrated period of high semen demand. For conventional semen straws, liquid semen has a distinct advantage over frozen semen because the reduced sperm concentration per straw (approximately $3-5 \times 10^{6}$ vs. $15-20$ $\times 10^{6}$ sperm, respectively; Murphy et al., 2015) allows for approximately 3 to 5 times more semen straws to be produced per ejaculate. A limited number of studies have been carried out with fresh SS. One study in New Zealand $(\mathrm{Xu}, 2014)$ reported average nonreturn rates over 3 seasons (2011, 2012, and 2013) that were $94.6 \%$ of those achieved with conventional semen at $24 \mathrm{~d}$ after AI in dairy cows inseminated with fresh SS $(1.25-2 \times$ $10^{6}$ sperm per straw). Nevertheless, fresh SS is currently a niche product. With the current technology, speed of sperm sorting is a limiting factor for the availability of fresh SS. Consequently, it could not cater for widespread usage during the period of concentrated demand ( $\sim 6$ wk) that occurs in countries with seasonal-calving systems. Hence, evaluating the fertility performance of both fresh and frozen SS in a large controlled field trial is necessary.

Our objective was to investigate the phenotypic fertility performance of fresh and frozen SS compared with conventional semen in seasonal-calving pasture-based dairy herds. Ejaculates were split such that each treat- ment was represented in each ejaculate, and fertility performance of conventional and SS (fresh and frozen) was compared in both heifers and cows. We tested 2 hypotheses: (1) fresh SS would result in greater P/AI compared with frozen SS, and (2) increasing the concentration of sperm in fresh SS straws would increase P/AI. Preliminary results based on pregnancy exams at 55 to $80 \mathrm{~d}$ post-AI from a subsample $(\mathrm{n}=3,943)$ of the animals used in the present study were previously published (Butler et al., 2014a,b). Here, we present a more extensive and detailed study of the results based on data from a greater number of animals.

\section{MATERIALS AND METHODS}

All animal work was approved by the Teagasc Animal Ethics Committee. The herds enrolled in the study were all seasonally calving pasture-based dairy herds. The cows were predominantly Holstein-Friesian breed, and some crossbred cows were also present (especially Jersey and Norwegian Red). The typical diet at the start of the breeding season in this system is primarily grazed perennial ryegrass swards $(12-18 \mathrm{~kg} / \mathrm{d})$, supplemented with a variable quantity of concentrate feed depending on farm pasture availability $(0-6 \mathrm{~kg} / \mathrm{d})$. Average cow milk production at this stage of lactation typically ranges between 1.8 and $2.2 \mathrm{~kg}$ of milk solids (i.e., fat plus protein yield) or 25 to $28 \mathrm{~kg}$ of milk volume per day.

\section{Semen Collection and Processing}

The semen collection schedule and semen processing protocol are illustrated in Figure 1a. From April 15 to May 16, 2013, semen was collected from 18 Holstein-Friesian bulls using an artificial vagina at 1 of 3 European Union-approved semen collection centers: National Cattle Breeding Centre, Enfield, Co. Meath, Ireland $(\mathrm{n}=6)$; Munster Cattle Breeding Group, Mallow, Co. Cork, Ireland $(\mathrm{n}=6)$; and Dovea Genetics, Thurles, Co. Tipperary, Ireland $(\mathrm{n}=6)$. Individual bulls were collected every $3 \mathrm{~d}$ on a routine schedule for the duration of the 32-d collection period. Of the 18 bulls, 9 were identified as priority bulls, with the remaining 9 collected as reserve bulls for use in the event that a priority bull failed initial screening tests. Bulls were identified as priority or reserve at the time of study design, but if an individual bull was ultimately used in the study, no distinction was made between priority and back-up bulls in the data analysis. Raw ejaculates were transported in temperature-controlled boxes $\left(18^{\circ} \mathrm{C}\right)$ to a temporary semen laboratory operated by Sexing Technologies located on the Teagasc 
Moorepark Campus. Upon arrival at the laboratory, the raw (undiluted) semen was assessed with regard to concentration, subjective motility, and morphology. Sperm concentration was calculated using an automated cell counter (NucleoCounter; ChemoMetec A/S, Lillerød, Denmark); ejaculates containing $<1 \times 10^{9}$ sperm $/ \mathrm{mL}$ or $<5 \times 10^{9}$ total sperm were rejected. Subjective motility was assessed using a microscope, and a minimum of $65 \%$ motile sperm was required for processing. Sperm morphology was evaluated by differential interference contrast microscopy at $600 \times$ magnification in a $10-\mu \mathrm{L}$ sample of neat semen in $0.5 \mathrm{~mL}$ of Tyrode's albumin lactate pyruvate buffer containing $0.2 \%$ formalin. Abnormalities related to sperm head defects were classified as primary abnormalities, and defects involving the sperm tail were classified as secondary abnormalities (Barth and Oko, 1989). Ejaculates with $<75 \%$ normal sperm morphology were rejected.

Each acceptable ejaculate was initially split into 2 aliquots. One of the aliquots was processed as fresh conventional semen at $3 \times 10^{6}$ sperm per straw (CONV), whereas the other aliquot was sex-sorted for X chromosome-bearing sperm with a $\sim 90 \%$ purity using SexedULTRA sorting technology (Sexing Technologies, Navasota, TX) and following standard commercial procedures (Garner et al., 2013). The SS was subsequently processed to provide fresh SS at 1 $\times 10^{6}$ sperm per straw $(\mathbf{S S}-\mathbf{1 M})$, fresh SS semen at 2 $\times 10^{6}$ sperm per straw $(\mathbf{S S}-\mathbf{2 M})$, or frozen SS at $2 \times$ $10^{6}$ sperm per straw (SS-FRZ). Semen aliquots were incubated with Hoechst $33342(50.4 \mu M)$ in a water bath at $34^{\circ} \mathrm{C}$ for $45 \mathrm{~min}$. Sex sorting was conducted on a high-speed flow cytometer at 40 psi with a $70-\mu \mathrm{m}$ nozzle, vanguard laser set at $200 \mathrm{~mW}$, and event rate of 20,000 to 21,000 events per second. Once sorted, SS$1 \mathrm{M}$ and SS-2M were processed (reconcentration, final extension, and packaging in straws) at $18^{\circ} \mathrm{C}$, whereas SS-FRZ was processed at $5^{\circ} \mathrm{C}$.

All diluents were proprietary media supplied by Sexing Technologies. An optimized Tris-egg yolk buffer containing $6 \%$ glycerol was used as diluent for the SS-FRZ. Fresh semen (CONV, SS-1M, or SS-2M) was extended in a medium containing HEPES buffer and additives, which had previously been developed for use with conventional semen.

The SS-FRZ straws were frozen in liquid nitrogen vapor at rates within documented tolerance limits (Robbins et al., 1976) before being plunged into liquid nitrogen. Fresh semen straws (SS-1M, SS-2M, and CONV) were stored in temperature-controlled units $\left(18^{\circ} \mathrm{C}\right)$ until dispatch. All batches underwent quality control analysis before being released, including subjective assessment of sperm motility, acrosome integrity by differential interference contrast microscopy, and purity (i.e., X chromosome-bearing sperm population $\geq 87 \%$; Garner et al., 2013). In addition, thermal stress tolerance test (reduction in motility of the sperm population after $3 \mathrm{~h}$ of incubation at $37^{\circ} \mathrm{C}$ ) was performed with the frozen straws, and the motility of sperm in the fresh straws was assessed 24 and $48 \mathrm{~h}$ after production.

\section{Distribution, Insemination, and Recording of Straws}

A courier network was established to distribute the semen straws from the sorting laboratory to participating AI technicians for the duration of the trial (Figure 1b). Ejaculates were collected from bulls at the different studs at $2000 \mathrm{~h}(\mathrm{~d}-1), 0400 \mathrm{~h}(\mathrm{~d} 0)$, and $1000 \mathrm{~h}$ (d 0 ) and were delivered to the laboratory within $4 \mathrm{~h}$ of collection. Ejaculates were processed and released for distribution to AI technicians at $1800 \mathrm{~h}$ (d 0), and inseminations were conducted starting at $0700 \mathrm{~h}(\mathrm{~d} 1)$ the following day and continuing until $1900 \mathrm{~h}$ the day after (d 2). The average time interval from semen collection to first use in the field was 35,27 , and $21 \mathrm{~h}$ for the first, second, and third bulls on the collection schedule, respectively. The time interval from semen dispatch to first use in the field was $\sim 13 \mathrm{~h}$. Each AI technician received an allocation of straws every second day to ensure balanced use of the fresh semen on $\mathrm{d} 1$ and 2. The semen dispatch schedule ensured that every AI technician received straws from all bulls.

A total of 110 AI technicians were involved in the study and were provided with guidelines on optimal handling techniques for both fresh and frozen SS. Inseminations were performed during a 34 -d period from April 15 to May 18, 2013. Every insemination was recorded on a handheld computer, and the information was subsequently exported to the Irish Cattle Breeding Federation database, which is a repository for animal records, events, and performance data for all of the cattle registered in Ireland and the herds in which they reside. In total, 15,145 inseminations on 492 farms were recorded. At 55 to $80 \mathrm{~d}$ post-AI, the BCS (1-5 scale; Edmonson et al., 1989) was recorded for 3,943 of the animals by 1 of 2 highly experienced personnel. Additional animal information was also retrieved from the Irish Cattle Breeding Federation database including calving date, parity, Economic Breeding Index (EBI), and PTA (i.e., average genetic value for a given trait that an animal transmits to its offspring) values for genetic traits of interest. The EBI is a single figure profit index used in Ireland to identify animals with superior genetic merit (Teagasc, 2014). It is composed of 7 subindexes with different weights (in parentheses): fertility (35\%), milk production (33\%), calving performance $(9 \%)$, beef performance $(9 \%)$, cow maintenance $(7 \%)$, cow management (4\%), and health $(3 \%)$ subindexes. 
The fertility subindex is calculated based on calving survival (24\%) and survival (11\%), whereas the milk production subindex is calculated based on kilograms of milk protein (19\%), milk (11\%), and milk fat (3\%).

\section{Data Handling}

Observations with calving-to-AI intervals (i.e., DIM at $\mathrm{AI}$ ) $>140 \mathrm{~d}$ were assumed to indicate cows that had

(a)

\begin{tabular}{|c|c|c|c|c|c|c|c|c|}
\hline \multicolumn{3}{|c|}{ Day 1} & \multicolumn{3}{|c|}{ Day 2} & \multicolumn{3}{|c|}{ Day 3} \\
\hline 4 a.m. & 10 a.m. & 8 p.m. & 4 a.m. & 10 a.m. & 8 p.m. & $4 \mathrm{a} . \mathrm{m}$. & 10 a.m. & 8 p.m. \\
\hline Bull 1 & Bull 2 & Bull 3 & Bull 4 & Bull 5 & Bull 6 & Bull 7 & Bull 8 & Bull 9 \\
\hline Bull 10 & Bull 11 & Bull 12 & Bull 13 & Bull 14 & Bull 15 & Bull 16 & Bull 17 & Bull 18 \\
\hline
\end{tabular}

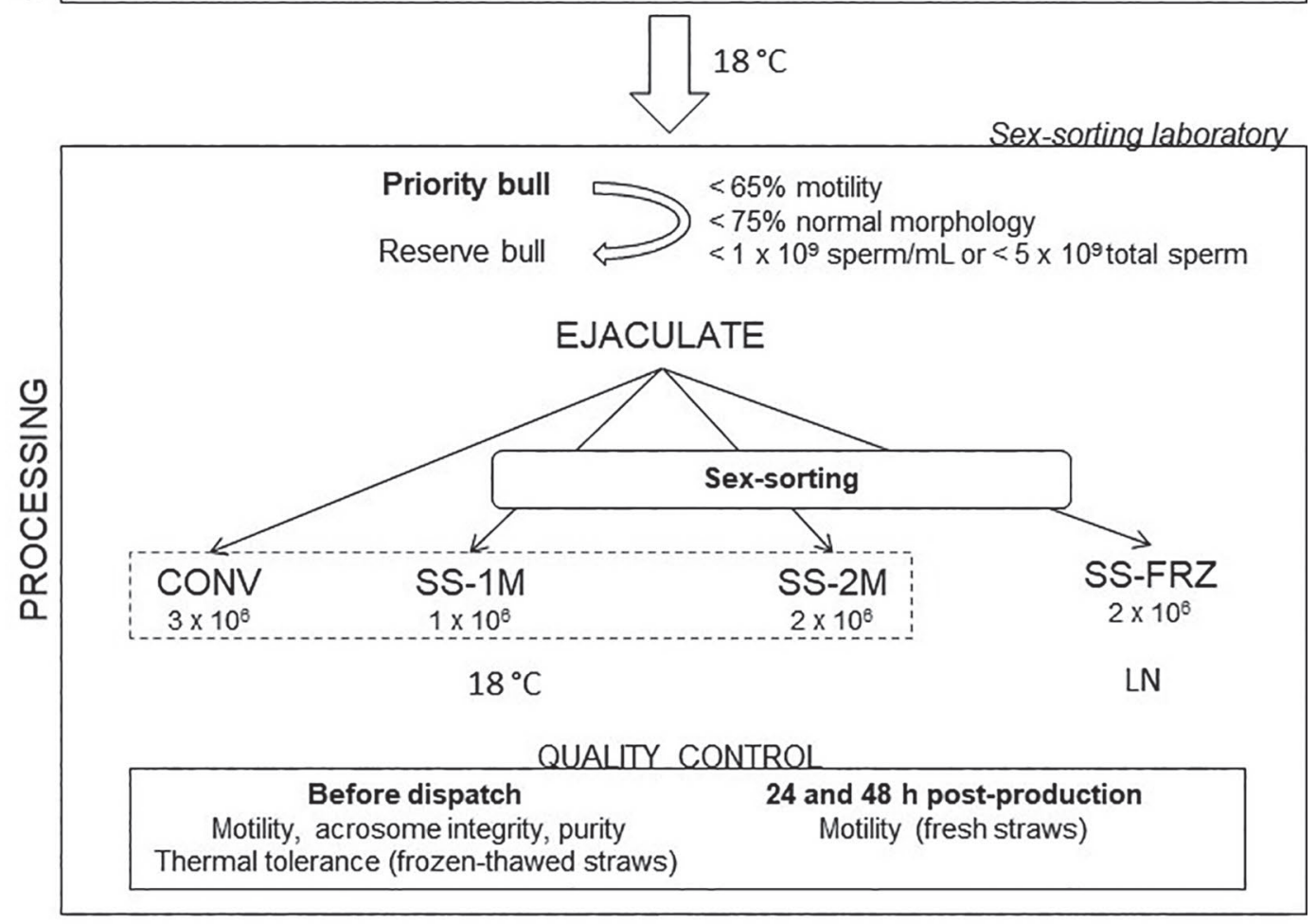

(b)

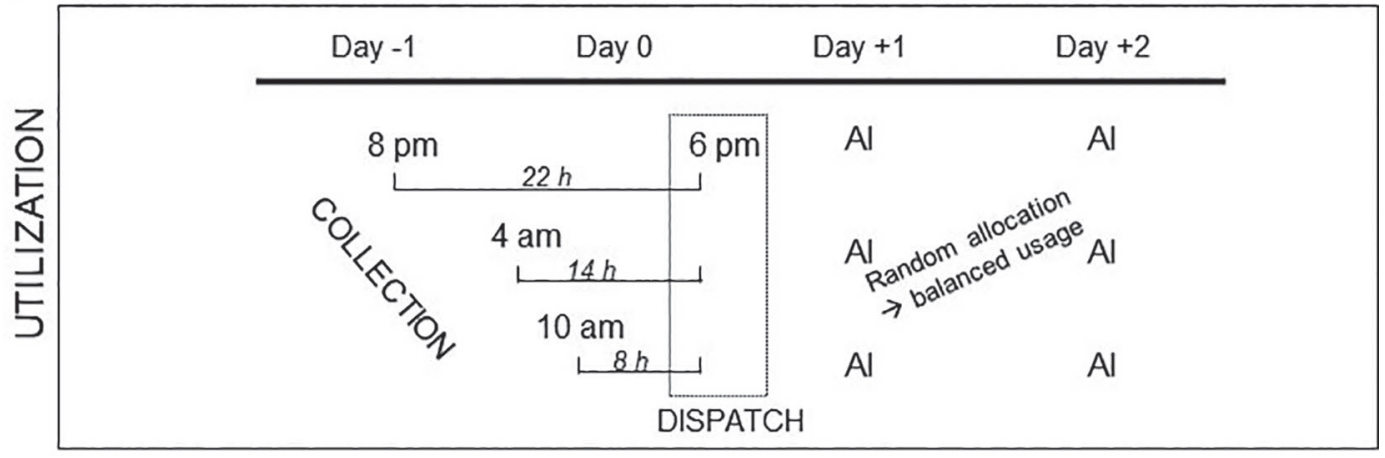

Figure 1. Experimental design. (a) Collection schedule (3-d cycle) and processing of the ejaculates. Quality control (QC); fresh conventional semen $(\mathrm{CONV})$; fresh sex-sorted semen at $1 \times 10^{6}$ sperm/straw (SS-1M) or at $2 \times 10^{6} \mathrm{sperm} / \mathrm{straw}$ (SS-2M); frozen sex-sorted semen (SS-FRZ); liquid nitrogen (LN). (b) Utilization. The day of dispatch is considered d 0. Interval from collection to dispatch (hours) is in italics. 
calved before the current seasonal cohort (i.e., carryover cows from a previous autumn- or spring-calving period), and were removed from the data set. After removal of observations with missing values in the variables of interest, the data set consisted of 12,251 observations; of these, 3,222 observations included a BCS record. Only insemination events conducted on $\mathrm{d} 1$ and 2 after dispatch were retained for analysis (including frozen SS treatment). The data set was then checked for duplicates, and only cows that received a trial straw insemination at the first AI were retained. After this, the total number of observations was reduced to 11,400. The data set was subsequently constrained so that only bulls with $\geq 300$ inseminations were used. Ten bulls remained, and the total observations were 11,274 at this point. After removal of herds with $<16$ inseminations (4 treatments $\times 4$ replicates/herd), the total number of insemination records was reduced to 9,963. The data set was split into parity $=0$ (heifers, $\mathrm{n}=3,733$ ) and parity $\geq 1$ (lactating cows, $\mathrm{n}=6,230$ ). Pregnancy per $\mathrm{AI}$ at the first insemination using trial semen straws was the primary outcome variable of interest. Pregnancy status was coded as 1 (i.e., successful) if either of 2 criteria was met: (1) cows were diagnosed as pregnant following ultrasound examination, or (2) no record of a subsequent insemination was found and the interval from AI to subsequent calving was $\geq 270$ and $\leq 292 \mathrm{~d}$. Otherwise, pregnancy status was coded as 0 (i.e., unsuccessful).

\section{Statistical Analysis}

Generalized linear mixed models (PROC GLIMMIX, SAS 9.4, SAS Institute, Cary, NC) for data with a binary distribution, with residual pseudo-likelihood as estimation technique and Kenward-Roger method for calculation of the degrees of freedom, were used to evaluate the effect of semen treatment on $\mathrm{P} / \mathrm{AI}$ in heifers and lactating cows. Data for heifers and lactating cows were analyzed separately because some variables included in the analysis only affected cows (e.g., parity, DIM). The animal that received the insemination event (heifer or cow) was designated as the experimental unit. Semen treatment, bull, and treatment by bull interaction were always included in the model as fixed effects, and farm was included as a random effect. Several covariates (such as EBI, EBI fertility, and milk production subindexes; PTA for calving interval, survival, milk protein $\%$, and milk kg; parity; and DIM), interactions and quadratic (i.e., squared) terms for continuous variables were tested for inclusion (backward stepwise regression) and retained as fixed effects for the final model when $P \leq 0.25$. Quadratic terms, such as $\mathrm{DIM}^{2}$, can be used when a curvilinear instead of linear relationship between variables (e.g., P/AI and DIM) is suspected. The inclusion of a quadratic term transforms a linear regression model into a curve without having to model a nonlinear model because the independent variable is squared but not the $\beta$-coefficient. Comparisons of least squares means (LSM) for P/AI between semen treatments, parities, bulls, and bull by semen treatment interactions were performed using Tukey-Kramer adjustment for multiple comparisons. A significant difference or effect was considered to exist when $P<0.05$. Results are reported as statistic \pm standard error of the statistic (e.g., $\mathrm{LSM} \pm \mathrm{SEM}$ ).

Regression Model for Heifers. Fixed effects retained for the final heifer model were semen treatment, bull, semen treatment by bull interaction, and PTA for milk protein percentage. Herd was included as a random effect.

Regression Model for Lactating Cows. Fixed effects retained for the final cow model were: semen treatment, bull, semen treatment by bull interaction, parity $(1,2,3,4,>4)$, DIM, DIM ${ }^{2}$, EBI, and EBI milk production subindex. Herd was included as a random effect.

Dispatch-to-AI Interval. An additional model was run to examine the effect that dispatch-to-AI interval had on $\mathrm{P} / \mathrm{AI}$ of heifers and cows inseminated with fresh semen (CONV, SS-1M, or SS-2M). The same fixed effects as in previous models for heifers (semen treatment, bull, semen treatment $\times$ bull interaction, and PTA for milk protein \%) or cows (semen treatment, bull, semen treatment $\times$ bull interaction, parity, DIM, $\mathrm{DIM}^{2}, \mathrm{EBI}$, and EBI milk production subindex) were included, with the addition of dispatch-to-AI interval and bull $\times$ dispatch-to-AI interval interaction. Herd was included as a random effect in both models.

\section{Surface Plots}

Based on the data set of the lactating cows, surface plots for the probability of pregnancy (equivalent to $\mathrm{P} / \mathrm{AI}$, but expressed as a proportion) of young (parity $\leq 2$ ) cows inseminated with fresh or frozen SS at $2 \times$ $10^{6}$ sperm per straw (SS-2M and SS-FRZ) were generated (PROC G3D, SAS 9.4) pairing the variables BCS, DIM, and EBI fertility subindex. Surface plots are 3-dimensional graphs that show a functional relationship between a dependent variable ( $y$-axis; probability of pregnancy) and 2 independent variables ( $x$ - and $z$ axis). For each surface plot, 2 independent variables were paired and plotted, and the remaining 2 were held at selected values that defined an elite group of cows: BCS $\geq 3$, DIM $>60 \mathrm{~d}$, and fertility subindex $>€ 100$. 


\section{RESULTS}

\section{Bulls}

The final analysis included a total of 10 HolsteinFriesian bulls. Of these, 9 were initially identified as priority bulls and 1 as a reserve bull. Their average EBI in April 2013 was $€ 238 \pm 7$, with a reliability ranging from 51 to $89 \%$.

\section{Heifers}

Of the 3,733 heifers with $\mathrm{P} / \mathrm{AI}$ data, a complete data set with all covariates of interest was available for 3,214 heifers in 199 herds for the final analysis. Semen treatment affected $(P<0.05) \mathrm{P} / \mathrm{AI}$ in heifers. Heifers inseminated with CONV had greater $\mathrm{P} / \mathrm{AI}$ than those inseminated with SS-FRZ but were not different from heifers inseminated with either of the fresh SS treatments (SS-1M or SS-2M). None of the SS treatments differed from each other in terms of $\mathrm{P} / \mathrm{AI}$ (Table 1 ). Bull affected $\mathrm{P} / \mathrm{AI}$ in heifers $(P<0.001)$, which ranged from 31.6 to $64.3 \%$. Bull 10 achieved the lowest P/AI and differed from all other bulls except bull 9 (Figure 2a). No interaction occurred between bull and semen treatment $(P=0.157)$. Nevertheless, LSM of $\mathrm{P} / \mathrm{AI}$ for each semen treatment within bull are plotted in Figure 2b; P/AI achieved did not differ $(P>0.05)$ between semen treatments within any individual bull. Pregnancy per AI increased $(P<0.001)$ with increasing PTA for milk protein percent.

This analysis only used data from heifers inseminated with any of the fresh semen treatments (CONV, SS-1M, and SS-2M; $\mathrm{n}=4,292)$. Dispatch-to-AI interval did not affect $\mathrm{P} / \mathrm{AI}$ in heifers inseminated with fresh semen, and we did not observe any dispatch-to-AI interval by bull interaction (both $P>0.05$ ).

\section{Lactating Cows}

Of the 6,230 cows with $\mathrm{P} / \mathrm{AI}$ data, a complete data set with all covariates of interest was available for 5,493 cows in 238 herds for the final analysis. Semen treatment affected $(P<0.001) \mathrm{P} / \mathrm{AI}$ in lactating cows. Lactating cows inseminated with CONV had greater $\mathrm{P} / \mathrm{AI}$ than those inseminated with any of the SS treatments (SS-1M, SS-2M, or SS-FRZ), but P/AI did not differ between the SS treatments (Table 1). Bull affected $\mathrm{P} / \mathrm{AI}(P<0.001)$ in lactating cows. For comparison purposes, bulls were numbered in the order of the $\mathrm{P} / \mathrm{AI}$ achieved with heifers previously illustrated in Figure 2 (Figure 3a). Bull 10 achieved the lowest $\mathrm{P} / \mathrm{AI}(14.4 \%)$ and was different from all other bulls (range 39.9-47.9\%). No bull by semen treatment interaction occurred $(P=0.127)$. Within bull, a significant effect of semen treatment on $\mathrm{P} / \mathrm{AI}$ was detected for 1 bull only (bull 10, Figure 3b), with SS-2M achieving a lower P/AI than CONV (5.3 vs. 26.7\%, respectively). Parity influenced $\mathrm{P} / \mathrm{AI}(P<0.001)$; cows in parities 1,2 , and 3 had greater P/AI $(45.2,44.0$, and $42.8 \%$, respectively) compared with cows in parity $\geq 5(34.4 \%$; all $P<0.01$ ), and cows in parity 4 were intermediate (40.2\%; not different from other parities). Pregnancy per AI of lactating cows increased with increasing EBI but decreased with increasing milk subindex of the EBI (both $P<0.001$ ). Pregnancy per AI of lactating cows increased with increasing DIM; however, it decreased when DIM was considered as a quadratic $\left(\mathrm{DIM}^{2}\right.$; both $P<0.001)$.

Effect of Dispatch-to-AI Interval on Fresh Semen Treatments. This analysis only used data from lactating cows inseminated with any of the fresh semen treatments (CONV, SS-1M, and SS-2M; $\mathrm{n}=4,292$ ). Dispatch-to-AI interval did not affect $(P=0.403) \mathrm{P} / \mathrm{AI}$ of lactating cows inseminated with fresh semen. However, a dispatch-to-AI interval by bull interaction existed $(P<0.01)$. Bulls 4 and 6 were combined (group 1$)$ and plotted (Figure 4) against the other bulls combined (group 2): $\mathrm{P} / \mathrm{AI}$ of group 1 increased (slope $=0.021 ; P$ $<0.001)$ as dispatch-to-AI interval increased, whereas $\mathrm{P} / \mathrm{AI}$ of group 2 slightly decreased although without statistical significance (slope $=-0.003 ; P>0.05$ ).

Surface Plots. This analysis used data from elite lactating cows (parity $\leq 2$ and BCS, DIM, or EBI fertility subindex held at selected values) inseminated with SS-2M or SS-FRZ. For elite cows of BCS $\geq 3$ ( $\mathrm{n}=$ 2,313 ; Figure 5a), those with a fertility subindex $<€ 100$ did not reach a probability of pregnancy equivalent to those whose fertility subindex $\geq € 100$. In elite cows with a fertility subindex $>€ 100(\mathrm{n}=848$; Figure $5 \mathrm{~b})$, the probability of pregnancy increased with greater BCS, especially in a comparison of cows of BCS $<3$ to cows of BCS $\geq 3.0$, and independently of DIM. In elite cows with $>60$ DIM at AI $(\mathrm{n}=1,763$; Figure $5 \mathrm{c})$, the probability of pregnancy was greater for those with a BCS $\geq 3.0$ than for those with a BCS $<3.0$, independent of fertility subindex. Additionally, probability of pregnancy increased with fertility subindex for these elite when their BCS was $\leq 3$.

\section{DISCUSSION}

This study used split ejaculates to compare $\mathrm{P} /$ $\mathrm{AI}$ achieved with various $\mathrm{SS}$ treatments versus $\mathrm{P} / \mathrm{AI}$ achieved with conventional semen in dairy heifers and lactating dairy cows. The main findings can be summa- 
Table 1. Least squares means \pm SEM for pregnancy per AI (P/AI) and performance of sex-sorted semen relative to conventional (SS/CONV $\times 100)$ after AI of dairy heifers and cows with fresh conventional semen (CONV), fresh sex-sorted semen at $1 \times 10^{6}$ sperm/straw $(\mathrm{SS}-1 \mathrm{M})$ or 2 $\times 10^{6}$ sperm/straw $(\mathrm{SS}-2 \mathrm{M})$, or frozen sex-sorted semen $(\mathrm{SS}-\mathrm{FRZ})$

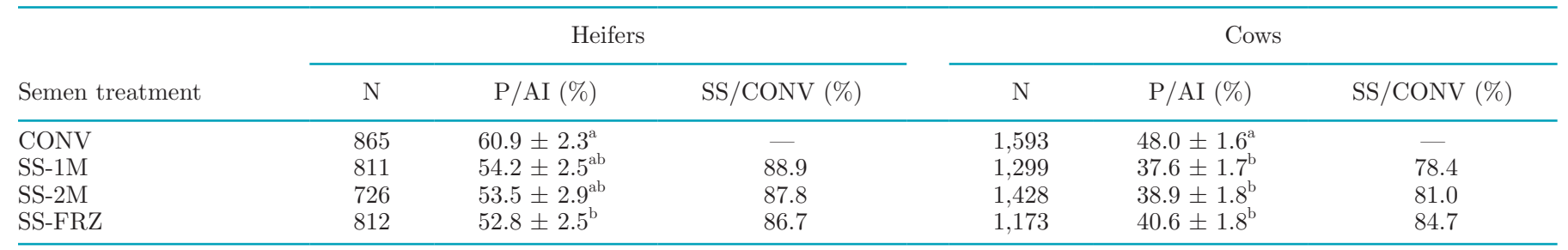

$\overline{\mathrm{a}, \mathrm{b}} \mathrm{LSM}$ within a column with different superscripts differ $(P<0.05)$.

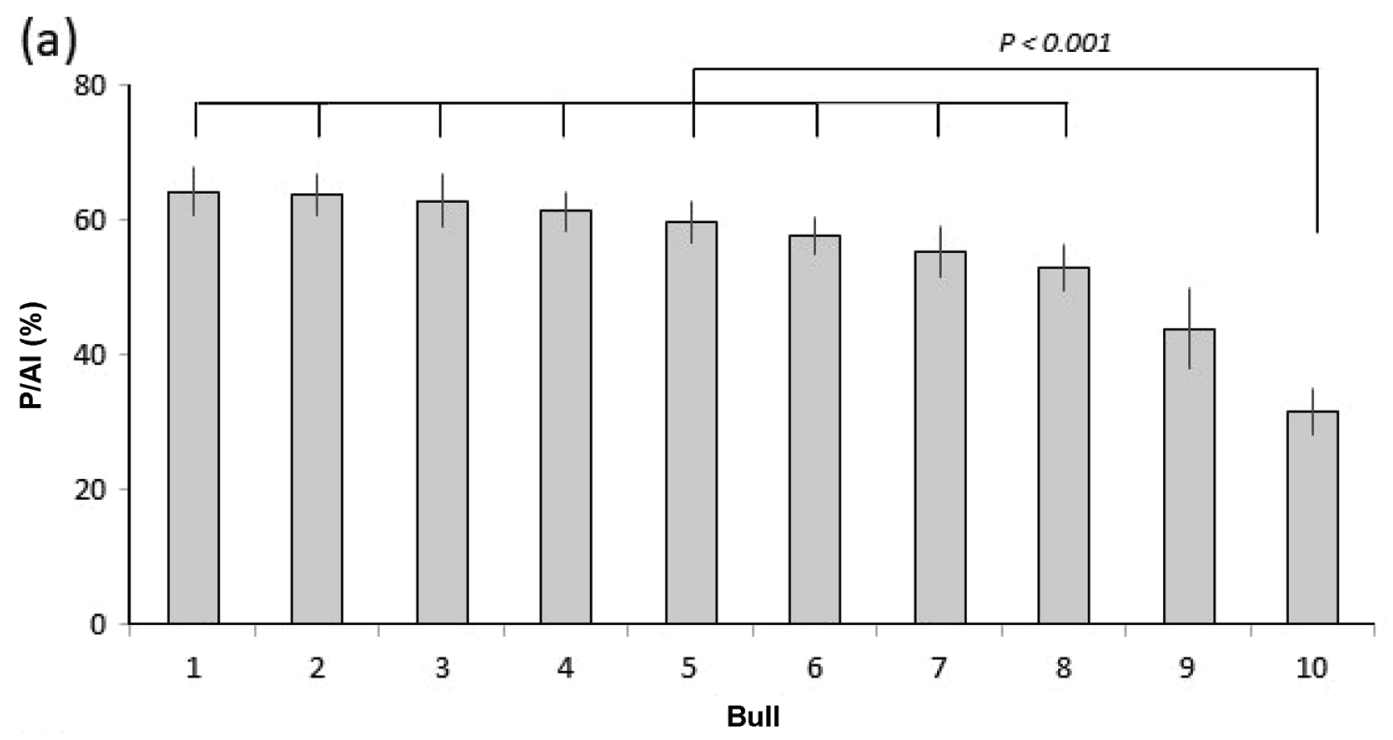

(b)

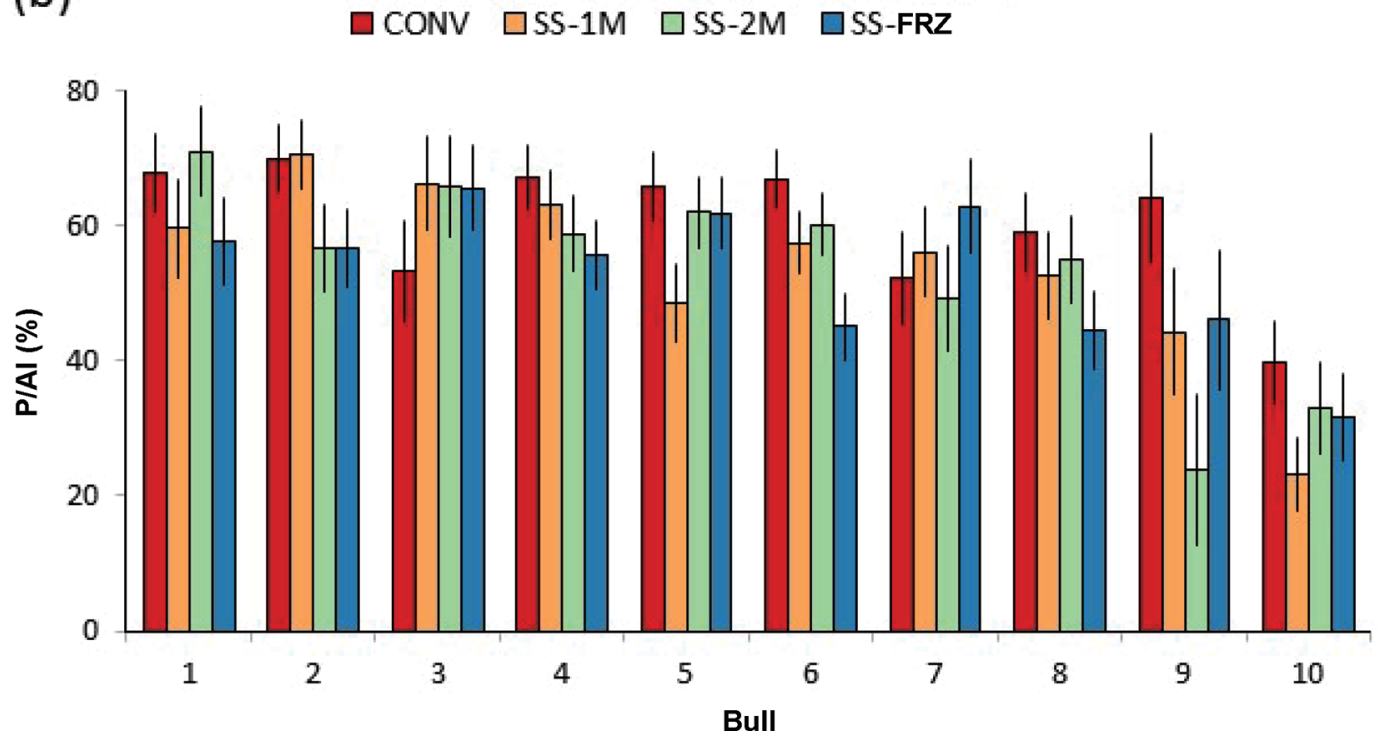

Figure 2. Effect of bull on pregnancy per AI (P/AI; LSM \pm SEM) of heifers across the 4 semen treatments (a) and by semen treatment (b). Fresh conventional semen (CONV); fresh sex-sorted semen at $1 \times 10^{6} \mathrm{sperm} /$ straw $(\mathrm{SS}-1 \mathrm{M})$; fresh sex-sorted semen at $2 \times 10^{6}$ sperm/straw (SS-2M); frozen sex-sorted semen (SS-FRZ). In panel (b), only differences between semen treatments within individual bulls are displayed; LSM did not differ $(P>0.05)$ between semen treatments within any individual bull. 
(a)
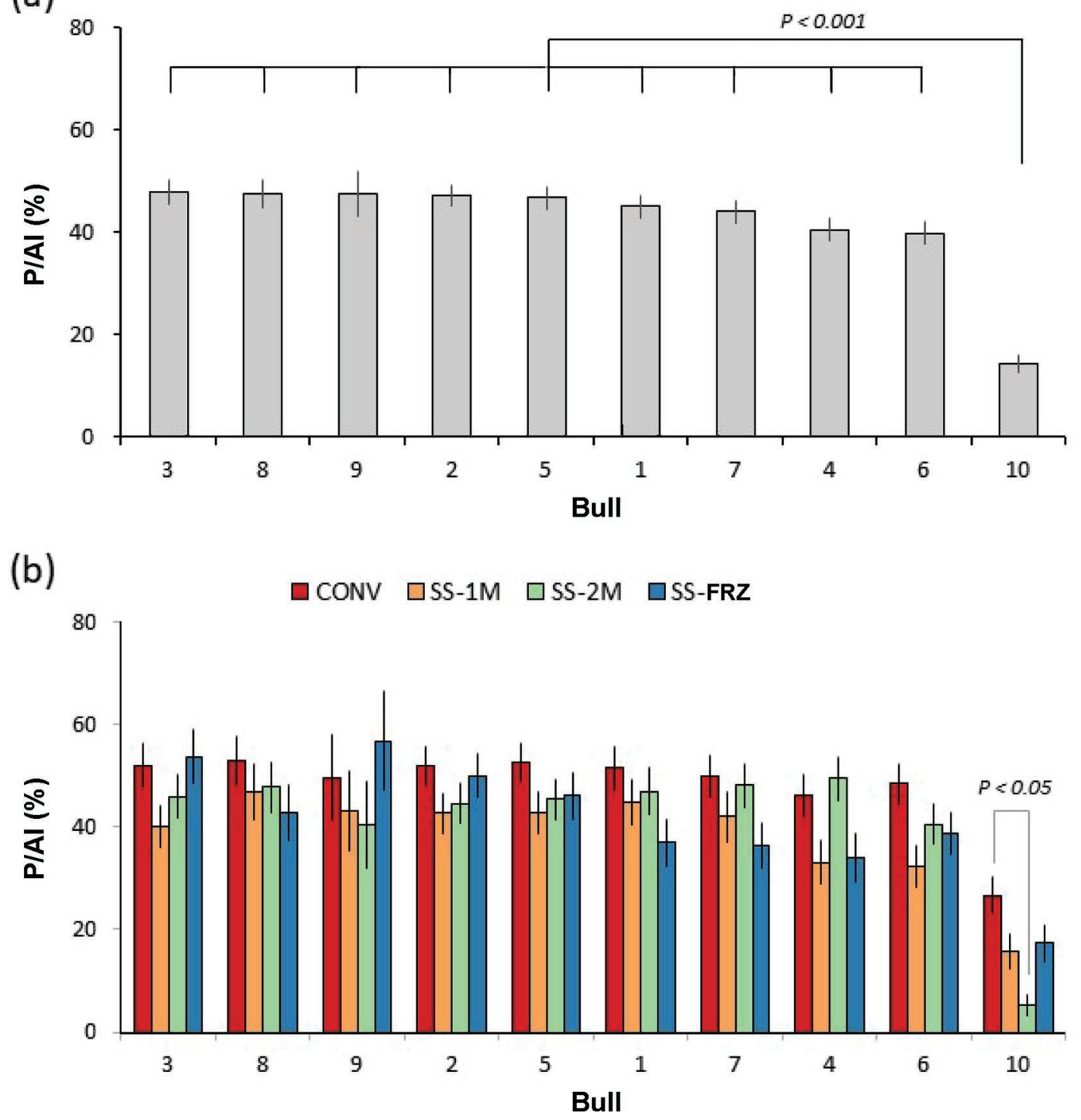

Figure 3. Effect of bull on pregnancy per AI (P/AI; LSM \pm SEM) of lactating cows across the 4 semen treatments (a) and by semen treatment (b). Fresh conventional semen (CONV); fresh sex-sorted semen at $1 \times 10^{6} \mathrm{sperm} / \mathrm{straw}(\mathrm{SS}-1 \mathrm{M})$; fresh sex-sorted semen at $2 \times 10^{6}$ sperm/ straw (SS-2M); frozen sex-sorted semen (SS-FRZ). In panel (b), only differences between semen treatments within individual bulls are displayed; LSM only differ $(P<0.05)$ between semen treatments (CONV vs. SS-2M) within bull 10.

rized as follows: (1) heifers inseminated with SS-FRZ had lower $\mathrm{P} / \mathrm{AI}$ than those inseminated with $\mathrm{CONV}$, whereas lactating cows inseminated with any of the SS treatments had lower P/AI than those inseminated with CONV; (2) P/AI achieved with frozen SS did not differ from that achieved with fresh SS; (3) doubling the concentration of sperm in fresh SS straws did not improve $\mathrm{P} / \mathrm{AI}$; (4) SS achieved relative $\mathrm{P} / \mathrm{AI}$ ranging from 78.4 to $88.9 \%$ of those achieved with $\mathrm{CONV}$; and (5) $\mathrm{P} / \mathrm{AI}$ achieved with SS was strongly affected by bull.

Sperm characteristics varied between ejaculates during quality assessment, and evidence of straw-to-straw variation within the same ejaculate was found (Utt, 2016; Harstine et al., 2018). Such variation makes assessment of bull fertility, both in vivo and in vitro, challenging. One significant weakness in most previously published studies on SS is the fact that treatments were applied to different ejaculates. Indeed, in some studies, different bulls were used for the SS and conventional treatments (Chebel et al., 2010; Xu, 2014); in others, different ejaculates from the same bull were used (DeJarnette et al., 2009, 2011; Norman et al., 2010). A recent trial in Germany (Lenz et al., 2016) aliquotted the ejaculate for the different SS treatments $(n=4)$, but used different contemporaneous ejaculates for the 
conventional semen treatment. To our knowledge, only a Danish field trial (Borchersen and Peacock, 2009) applied SS and conventional semen treatments to aliquots from the same ejaculate. In that study, however, only heifers were inseminated, and the number of inseminations was relatively low $(2,087$ doses in total, of which 735 were from Holstein bulls) and was unbalanced between treatments ( 554 heifers for SS vs. 181 for conventional). Here, we used a rigorous split-ejaculate technique, in which all 4 treatments were applied to each ejaculate from each bull to mitigate against ejaculate-to-ejaculate variability. Moreover, all fresh semen straws (SS-1M, SS-2M, and CONV) were processed at the same temperature $\left(18^{\circ} \mathrm{C}\right)$ and extended with the same diluent.

In lactating cows, both fresh SS treatments achieved lower $\mathrm{P} / \mathrm{AI}$ than $\mathrm{CONV}$, and the $\mathrm{P} / \mathrm{AI}$ achieved with $\mathrm{SS}$ relative to CONV with either $1 \times 10^{6}$ or $2 \times 10^{6}$ sperm per straw was less than previously reported in a pasture-based system with $1 \times 10^{6}$ sperm per straw (24-d nonreturn rates with fresh $\mathrm{SS}=94 \%$ of conventional; Xu, 2014). In heifers, although P/AI achieved by both fresh SS treatments were not statistically different
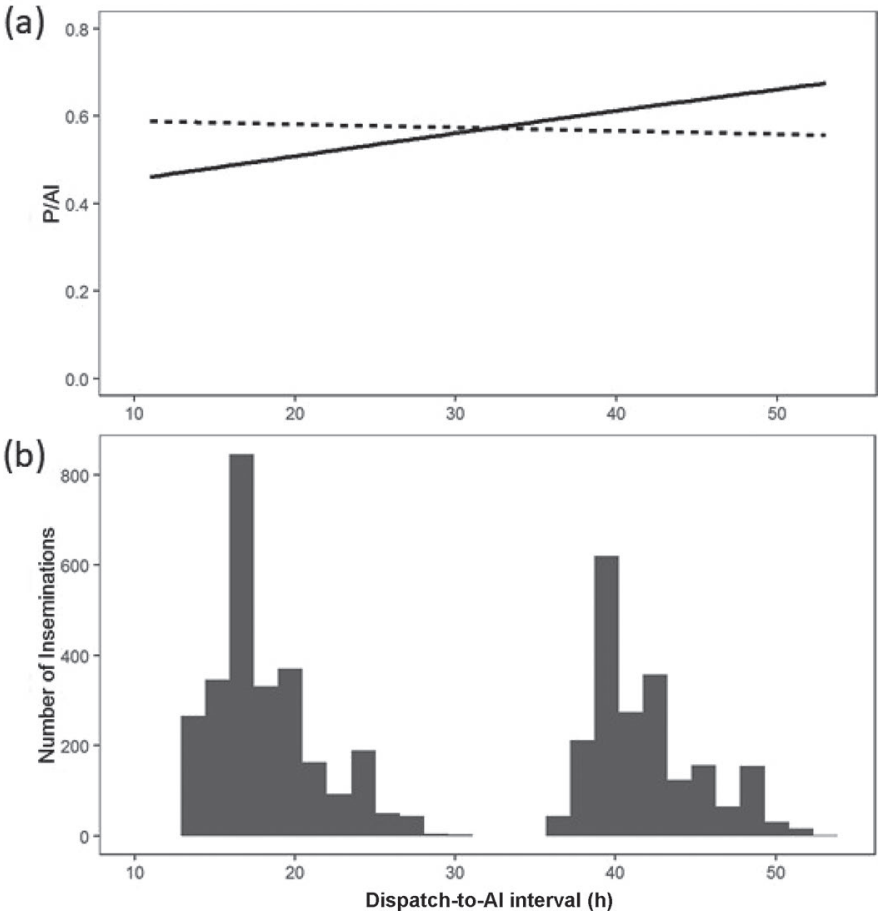

Figure 4. Effect of dispatch-to-AI interval on pregnancy per AI (P/AI) of lactating cows inseminated with fresh semen treatments (CONV, SS-1M, and SS-2M). (a) Bulls 4 and 6 are combined in group 1 (solid line), and the other bulls are combined in group 2 (dashed line); (b) histogram illustrating the time relative to dispatch when the fresh semen was used for AI. Fresh conventional semen (CONV); fresh sex-sorted semen at $1 \times 10^{6}$ sperm/straw (SS-1M); fresh sex-sorted semen at $2 \times 10^{6} \mathrm{sperm} /$ straw $(\mathrm{SS}-2 \mathrm{M})$. (a)

BCS $\geq 3$ and Parity $\leq 2$

a

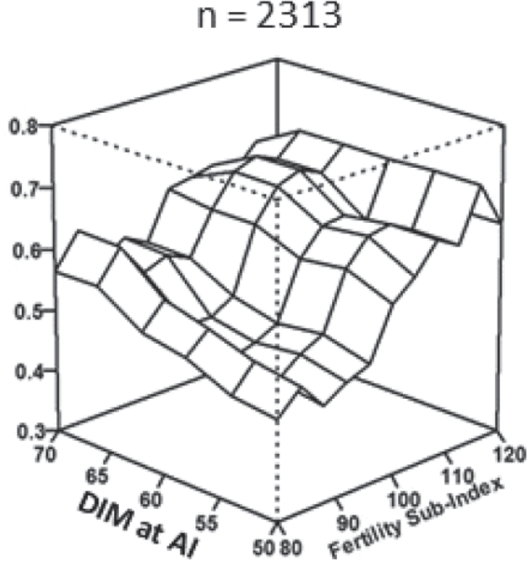

(b) Fertility SI $>€ 100$ and Parity $\leq 2$ $\mathrm{n}=848$

ฉ.

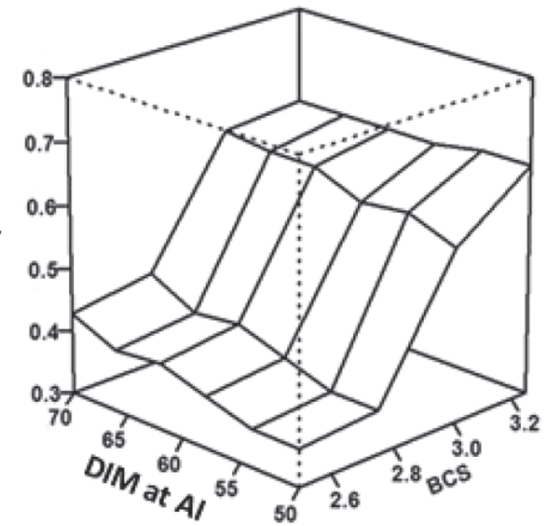

(c) $\mathrm{DIM}>60$ and Parity $\leq 2$ $\mathrm{n}=1763$

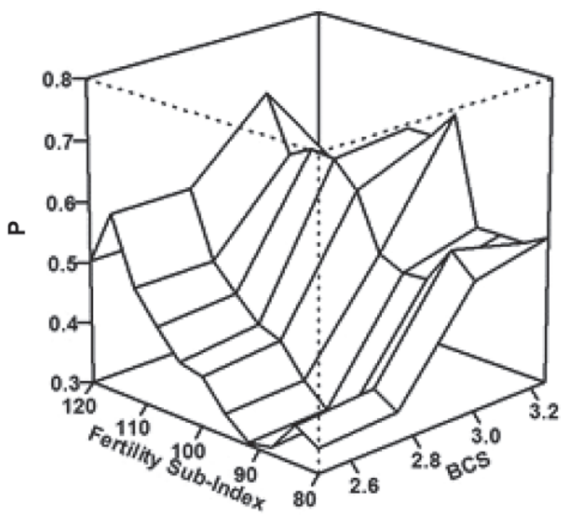

Figure 5. Surface plots for probability of pregnancy (P) of young lactating cows (parity $\leq 2$ ) inseminated with SS-2M or SS-FRZ and defined by BCS, DIM, and fertility subindex (SI) of the Economic Breeding Index. The value for $\mathrm{P}$ is equivalent to pregnancy per AI (P/ AI), but expressed as a proportion. The plots show possible pairings of the variables, holding the remaining 2 (shown above each panel) at selected values that define an elite group of cows: $\mathrm{BCS} \geq 3$, DIM $>60$ $\mathrm{d}$, and fertility subindex $>€ 100$. 
from CONV, they tended to be lower $(P<0.10)$. The reason for different findings for fresh SS in the current study compared with $\mathrm{Xu}$ (2014) is unclear, but it is likely related to differences in the media used (HEPESbased medium vs. Caprogen medium, respectively). Using representative straws generated for the current study, Holden et al. (2017) reported abnormally high levels of sperm agglutination $(>20 \%)$ in both fresh SS treatments (SS-1M and SS-2M), which was associated with lower progressive motility. These high levels of agglutination could affect sperm transport to the site of fertilization, and they could have contributed to the somewhat lower reproductive performance achieved by the fresh SS treatments in the current study compared with Xu (2014).

Despite having a long lifespan, frozen semen straws are costly to store because of the use of liquid nitrogen. The storage of fresh semen straws is inexpensive and its fertility, when stored at ambient temperature, is maintained for 3 to $5 \mathrm{~d}$, after which it gradually decreases (Vishwanath and Shannon, 1997). Consequently, fresh semen is generally used within $3 \mathrm{~d}$ after collection (Murphy et al., 2015). Cryopreservation alters sperm structure and function (Pini et al., 2018), and a significant proportion of sperm are nonviable after thawing. Hence, significantly more fresh straws can be produced per ejaculate because fewer sperm per straw are required to achieve similar P/AI to frozen semen (Shannon and Vishwanath, 1995). Xu (2014) suggested that the improved reproductive performance observed with fresh SS (94\% 24-d nonreturn rates relative to nonsorted) compared with frozen SS in previous studies may have been a consequence of a reduction in cryopreservation damage. Moreover, cryopreservation could have an additive damaging effect on the sperm already somewhat compromised by the sorting process. Xu (2014) did not include a frozen SS treatment against which to compare fresh SS. We hypothesized that fresh SS $\left(1 \times 10^{6}\right.$ and $2 \times 10^{6}$ sperm per straw) would result in greater $\mathrm{P} /$ AI than SS-FRZ $\left(2 \times 10^{6}\right.$ sperm per straw $)$. However, $\mathrm{P} / \mathrm{AI}$ did not differ between fresh and frozen SS treatments. Moreover, SS-FRZ had a better P/AI relative to conventional $(>84 \%)$ in heifers and lactating cows than found in previous studies (DeJarnette et al., 2009, 2010, 2011; Chebel et al., 2010; Norman et al., 2010; Sales et al., 2011; Healy et al., 2013; Djedović et al., 2016). To our knowledge, only 2 studies have reported greater $\mathrm{P} / \mathrm{AI}$ relative to conventional semen $(\geq 90 \%)$ than the current study with frozen SS at $2 \times 10^{6}$ sperm per straw (Borchersen and Peacock, 2009; Lenz et al., 2016), and both studies were conducted using heifers only. It is important to note, however, that since the current study was conducted, Sexing Technologies Inc. has increased the number of sperm in its commercially available SS from $2 \times 10^{6}$ to $4 \times 10^{6}$ sperm per straw. Nonreturn rates equivalent to conventional semen have been reported in dairy heifers when the sex-sorted sperm dose was increased to $4 \times 10^{6}$ sperm per straw (Lenz et al., 2016). Additional split-ejaculate studies are needed to examine the effects of the higher sperm dose in seasonal-calving pasture-based dairy cows and heifers.

A significant bull effect on P/AI was found in both lactating cows and heifers. Notably, one bull (bull 10) had poorer P/AI compared with all other bulls for cows and all other bulls except one for heifers, and it was ranked poorest for both cows and heifers. Additionally, the $\mathrm{P} / \mathrm{AI}$ of lactating cows inseminated with fresh semen (CONV, SS-1M, and SS-2M) varied between bulls as dispatch-to-AI interval increased. Although a statistical difference was only found between 2 treatments within 1 bull (CONV vs. SS-2M, bull 10), P/AI varied between treatments within bull (Figure 2b and $3 \mathrm{~b}$ ), in agreement with previous reports (Frijters et al., 2009; DeJarnette et al., 2010). Bulls are sometimes classified as "good freezers" or "poor freezers" with regard to their sperm susceptibility to cryopreservation (i.e., freezability). We observed that the inter- and intrabull variability may not be exclusive to the freezing process because it also appeared after sorting, as previously reported in boars (Parrilla et al., 2012). Even though all ejaculates passed the minimum quality control criteria to be released from the semen processing laboratory, we observed substantial variation between bulls in field fertility performance. Due to this inter- and intra-male variability, predicting whether an individual bull would achieve high or low P/AI with SS based on previous $\mathrm{P} / \mathrm{AI}$ data with conventional semen is challenging. Therefore, to reduce the risk involved in using bulls of unknown fertility with SS, or until in vitro tests can predict bull in vivo competence with SS, use of a large team of bulls for breeding management is recommended.

In the lactating cows in our study, P/AI increased with increasing EBI, which was expected due to the significant weighting on fertility in the index, but decreased with increasing milk subindex, that is, without considering the fertility subindex and only due to genetic merit for milk production. Regarding the positive relationship between P/AI and PTA for milk protein percentage in heifers, milk protein percentage has been positively associated with reproductive performance of pasture-based dairy cows (Patton et al., 2007; Yang et al., 2010; Morton et al., 2016). This positive relationship may be explained by the energy balance status during early lactation (Yang et al., 2010) and other 
factors during the rest of the lactation (Morton et al., 2016). Glucose is critical for the proper functioning of the hypothalamic-pituitary-ovarian axis (Butler, 2014). Moreover, reduced blood concentrations of glucose, insulin, IGF-1, and leptin are all associated with impaired reproductive performance (Butler, 2014). Douglas et al. (2016) found that cows with average milk protein percentage between 3.22 and $3.40 \%$ had greater postpartum blood concentrations of glucose, insulin, IGF-1, and leptin compared with those whose average milk protein percentage was between 2.87 and $3.00 \%$. Therefore, heifers with a higher PTA for milk protein percentage may be predisposed to having a better adaptation to lactation and subsequently superior reproductive performance.

The high cost of SS underlines the importance of achieving high $\mathrm{P} / \mathrm{AI}$. Heifers and young lactating cows are typically genetically superior and achieve greater P/AI compared with older cows. In this study, heifers had greater P/AI than lactating cows, in agreement with previous studies (DeJarnette et al., 2010; Norman et al., 2010). Moreover, P/AI in lactating cows decreased with increasing parity. Therefore, heifers and young lactating cows should be prioritized for insemination with SS. In an attempt to provide additional criteria to identify young cows (parity $\leq 2$ ) that are suitable for insemination with SS semen, we identified cow characteristics associated with greater likelihood of pregnancy establishment: BCS $\geq 3$, DIM $>60 \mathrm{~d}$, and fertility subindex of the EBI $>€ 100$. The effect of these parameters and their interactions on probability of pregnancy are illustrated using surface plots (Figure 5). Of the selected criteria, BCS was the most influential, followed by the fertility subindex; elite cows with BCS $\geq 3$ between 55 to $80 \mathrm{~d}$ post-AI always had an enhanced probability of pregnancy compared with cows with BCS $<3$, independent of their DIM (Figure 5b) or fertility subindex (Figure 5c). Cows with poor BCS are more likely to have experienced negative energy balance during the early postpartum period, with adverse consequences for subsequent reproductive performance. This highlights the importance of achieving the correct BCS at calving (3.00 or 3.25) and minimizing postpartum BCS loss ( $\leq 0.5$ units) in pasture-based cows (Butler, 2014; Bedere et al., 2018). Defining the elite cows allows targeted use of SS for a more profitable breeding strategy when the number of SS straws is limited (e.g., due to the high price of SS or inadequate availability of bulls in high demand).

Reduced in vivo fertility for SS is one of the main factors limiting widespread adoption, particularly in seasonal-calving pasture-based systems. Starting with the original XY technology, modifications to the protocol and optimization of media led to a new product called SexedULTRA, which was used for the present study, and previously during the last year of the 3-yr study by Xu (2014). Additional changes to the SexedULTRA semen processing methods have been implemented in recent years, resulting in better in vitro sperm quality parameters compared with the XY method (GónzalezMarín et al., 2016) and conventional semen (GonzálezMarín et al., 2018). In contrast to a previous study that indicated $\mathrm{P} / \mathrm{AI}$ achieved with $\mathrm{SS}$ using the XY technology was not compensable by increasing the number of sperm per straw (DeJarnette et al., 2011), 56-d nonreturn rates for heifers inseminated with the latest version of frozen SexedULTRA was dose dependent, and when the number of sperm processed using the SexedULTRA technology was increased to $4 \times 10^{6}$ per straw, nonreturn rates were equal to conventional semen straws containing $15 \times 10^{6}$ sperm per straw (Lenz et al., 2016; Vishwanath and Moreno, 2018). Collectively, these studies have demonstrated that SexedULTRA improved $\mathrm{P} / \mathrm{AI}$ relative to conventional semen versus historical reports using the XY technology, but SexedULTRA at $2 \times 10^{6}$ sperm per straw has not fully closed the fertility gap between conventional and SS. Further research is necessary to investigate the fertility performance of the latest generation of SexedULTRA containing $4 \times 10^{6}$ sperm per straw in heifers and cows managed under pasture-based systems.

In conclusion, frozen SS achieved $\mathrm{P} / \mathrm{AI}$ relative to conventional semen that were greater than previously reported in lactating cows. However, fresh SS did not achieve greater $\mathrm{P} / \mathrm{AI}$ than frozen $\mathrm{SS}$, regardless of whether the sperm dose per straw was $1 \times 10^{6}$ or $2 \times$ $10^{6}$. A bull effect for all semen treatments as well as a dispatch-to-AI interval by bull interaction for fresh semen underline the variable fertility performance observed and hence highlight the importance of using a large team of bulls for breeding management. The use of SS does not have to be limited to heifers; when using SS in lactating cows, P/AI can be increased by targeting SS to animals with the greatest likelihood of successful pregnancy establishment based on parity, BCS, EBI fertility subindex, and DIM.

\section{ACKNOWLEDGMENTS}

The authors gratefully acknowledge funding and support from Dovea Genetics (Thurles, Co. Tipperary, Ireland), Munster AI (Mallow, Co. Cork, Ireland), Progressive Genetics (Enfield, Co. Meath, Ireland), the National Cattle Breeding Centre (Naas, Co. Kildare, Ireland), ABP Food Group (Ardee, Co. Louth, Ireland), Dawn Meats (Grannagh, Co. Waterford, Ire- 
land), Kepak (Clonee, Co. Meath, Ireland), Slaney Linden Foods (Bunclody, Co. Wexford, Ireland), Irish Farmers Journal (Bluebell, Dublin 12, Ireland), Irish Cattle Breeding Federation (Bandon, Co. Cork, Ireland), and Teagasc (Oak Park, Co. Carlow, Ireland). We also gratefully acknowledge the work and assistance of Sexing Technologies. Our most sincere thanks to the AI technicians and farmers involved in the study. Clio Maicas was supported by a Teagasc Walsh Fellowship, and Ian Hutchinson was supported by a Teagasc postdoctoral fellowship.

\section{REFERENCES}

Barth, A. D., and R. J. Oko. 1989. Abnormal Morphology of Bovine Spermatozoa. 1st ed. Iowa State University Press, Ames, IA.

Bedere, N., E. Cutullic, L. Delaby, F. Garcia-Launay, and C. Disenhaus. 2018. Meta-analysis of the relationships between reproduction, milk yield and body condition score in dairy cows. Livest. Sci. 210:73-84. https://doi.org/10.1016/j.livsci.2018.01.017.

Borchersen, S., and M. Peacock. 2009. Danish A.I. field data with sexed semen. Theriogenology 71:59-63. https://doi.org/10.1016/j .theriogenology.2008.09.026.

Butler, S. T. 2014. Nutritional management to optimize fertility of dairy cows in pasture-based systems. Animal 8(Suppl. 1):15-26. https://doi.org/10.1017/S1751731114000834.

Butler, S. T., I. A. Hutchinson, and A. R. Cromie. 2014a. Preliminary results from a field trial to evaluate sexed semen in dairy cows and heifers. Page 115 in Proc. Agricultural Research Forum. Lynn Printers, Tullamore, Ireland.

Butler, S. T., I. A. Hutchinson, A. R. Cromie, and L. Shalloo. 2014b. Applications and cost benefits of sexed semen in pasture-based dairy production systems. Animal 8(Suppl. 1):165-172. https:// doi.org/10.1017/S1751731114000664.

Chebel, R. C., F. S. Guagnini, J. E. Santos, J. P. Fetrow, and J. R. Lima. 2010. Sex-sorted semen for dairy heifers: Effects on reproductive and lactational performances. J. Dairy Sci. 93:2496-2507. https://doi.org/10.3168/jds.2009-2858.

DeJarnette, J. M., M. A. Leach, R. L. Nebel, C. E. Marshall, C. R. McCleary, and J. F. Moreno. 2011. Effects of sex-sorting and sperm dosage on conception rates of Holstein heifers: Is comparable fertility of sex-sorted and conventional semen plausible? J. Dairy Sci. 94:3477-3483. https://doi.org/10.3168/jds.2011-4214.

DeJarnette, J. M., C. R. McCleary, M. A. Leach, J. F. Moreno, R. L. Nebel, and C. E. Marshall. 2010. Effects of 2.1 and $3.5 \times 10^{6}$ sex-sorted sperm dosages on conception rates of Holstein cows and heifers. J. Dairy Sci. 93:4079-4085. https://doi.org/10.3168/jds $.2010-3181$.

DeJarnette, J. M., R. L. Nebel, and C. E. Marshall. 2009. Evaluating the success of sex-sorted semen in US dairy herds from on farm records. Theriogenology 71:49-58. https://doi.org/10.1016/j .theriogenology.2008.09.042.

Djedović, R., V. Bogdanović, D. Stanojević, Z. Nemes, A. Gáspárdy, and S. Cseh. 2016. Involuntary reduction in vigour of calves born from sexed semen. Acta Vet. Hung. 64:229-238. https://doi.org/ 10.1556/004.2016.023.

Douglas, M. L., L. C. Marett, K. L. Macmillan, J. M. Morton, M. C. Hannah, A. D. Fisher, and M. J. Auldist. 2016. Associations of high and low milk protein concentrations with energy allocation, milk production, and concentrations of blood plasma metabolites and hormones in Holstein-Friesian cows. J. Dairy Sci. 99:1005710066. https://doi.org/10.3168/jds.2016-11388.

Edmonson, A. J., I. J. Lean, L. D. Weaver, T. Farver, and G. Webster. 1989. A body condition scoring chart for Holstein dairy cows. J. Dairy Sci. 72:68-78. https://doi.org/10.3168/jds.S0022 -0302(89)79081-0.
Faust, M. A., J. Betthauser, S. Crego, and A. Storch. 2016. Fertility and sex of calf results from a new commercial scale technology platform for producing sexed sperm. J. Anim. Sci. 94(Suppl. 5):544. (Abstr.) https://doi.org/10.2527/jam2016-1134.

Frijters, A. C., E. Mullaart, R. M. Roelofs, R. P. van Hoorne, J. F. Moreno, O. Moreno, and J. S. Merton. 2009. What affects fertility of sexed bull semen more, low sperm dosage or the sorting process? Theriogenology 71:64-67. https://doi.org/10.1016/j .theriogenology.2008.09.025.

Garner, D. L., K. M. Evans, and G. E. Seidel. 2013. Sex-sorting sperm using flow cytometry/cell sorting. Pages 279-295 in Spermatogenesis: Methods and Protocols. D. T. Carrell and K. I. Aston, ed. Humana Press, Totowa, NJ.

González-Marín, C., C. E. Góngora, T. B. Gilligan, K. M. Evans, J. F. Moreno, and R. Vishwanath. 2018. In vitro sperm quality and DNA integrity of SexedULTRA ${ }^{\mathrm{TM}}$ sex-sorted sperm compared to non-sorted bovine sperm. Theriogenology 114:40-45. https://doi .org/10.1016/j.theriogenology.2018.03.025.

Gónzalez-Marín, C., R. W. Lenz, T. B. Gilligan, K. M. Evans, C. E. Góngora, J. F. Moreno, and R. Vishwanath. 2016. SexedUL$\mathrm{TRA}^{\mathrm{TM}}$, a new method of processing sex sorted bovine sperm improves post-thaw sperm quality and in vitro fertility. Reprod. Fertil. Dev. 29:204. (Abstr.) https://doi.org/10.1071/RDv29n1Ab191.

Harstine, B. R., M. D. Utt, and J. M. DeJarnette. 2018. Review: Integrating a semen quality control program and sire fertility at a large artificial insemination organization. Animal 12(Suppl. 1):63-74. https://doi.org/10.1017/S1751731118000319.

Healy, A. A., J. K. House, and P. C. Thomson. 2013. Artificial insemination field data on the use of sexed and conventional semen in nulliparous Holstein heifers. J. Dairy Sci. 96:1905-1914. https:// doi.org/10.3168/jds.2012-5465.

Holden, S. A., C. Murphy, J. F. Moreno, S. T. Butler, A. R. Cromie, P. Lonergan, and S. Fair. 2017. In vitro characterisation of fresh and frozen sex-sorted bull spermatozoa. Reprod. Fertil. Dev. 29:1415-1425. https://doi.org/10.1071/RD16086.

Hötzel, M. J., C. Longo, L. F. Balcão, C. S. Cardoso, and J. H. C. Costa. 2014. A survey of management practices that influence performance and welfare of dairy calves reared in Southern Brazil. PLoS One 9:e114995. https://doi.org/10.1371/journal.pone.0114995.

Lenz, R. W., C. Gónzalez-Marín, T. B. Gilligan, J. M. DeJarnette, M. D. Utt, L. A. Helser, E. Hasenpusch, K. M. Evans, J. F. Moreno, and R. Vishwanath. 2016. SexedULTRA ${ }^{\mathrm{TM}}$, a new method of processing sex-sorted bovine sperm improves conception rates. Reprod. Fertil. Dev. 29:203-204. (Abstr.) https://doi.org/10.1071/ RDv29n1Ab190.

Morton, J. M., M. J. Auldist, M. L. Douglas, and K. L. Macmillan. 2016. Associations between milk protein concentration at various stages of lactation and reproductive performance in dairy cows. J. Dairy Sci. 99:10044-10056. https://doi.org/10.3168/jds.2016 $-11276$.

Murphy, C., S. A. Holden, E. M. Murphy, A. R. Cromie, P. Lonergan, and S. Fair. 2015. The impact of storage temperature and sperm number on the fertility of liquid-stored bull semen. Reprod. Fertil. Dev. 28:1349-1359. https://doi.org/10.1071/RD14369.

Murphy, C., L. Shalloo, I. A. Hutchinson, and S. T. Butler. 2016. Expanding the dairy herd in pasture-based systems: The role of sexed semen within alternative breeding strategies. J. Dairy Sci. 99:6680-6692. https://doi.org/10.3168/jds.2015-10378.

Norman, H. D., J. L. Hutchison, and R. H. Miller. 2010. Use of sexed semen and its effect on conception rate, calf sex, dystocia, and stillbirth of Holsteins in the United States. J. Dairy Sci. 93:38803890. https://doi.org/10.3168/jds.2009-2781.

Parrilla, I., D. del Olmo, L. Sijses, M. J. Martínez-Alborcia, C. Cuello, J. M. Vázquez, E. A. Martínez, and J. Roca. 2012. Differences in the ability of spermatozoa from individual boar ejaculates to withstand different semen-processing techniques. Anim. Reprod. Sci. 132:66-73. https://doi.org/10.1016/j.anireprosci.2012.04.003.

Patton, J., D. A. Kenny, S. McNamara, J. F. Mee, F. P. O'Mara, M. G. Diskin, and J. J. Murphy. 2007. Relationships among milk production, energy balance, plasma analytes, and reproduction in 
Holstein-Friesian cows. J. Dairy Sci. 90:649-658. https://doi.org/ 10.3168/jds.S0022-0302(07)71547-3.

Pini, T., T. Leahy, and S. P. de Graaf. 2018. Sublethal sperm freezing damage: Manifestations and solutions. Theriogenology 118:172181. https://doi.org/10.1016/j.theriogenology.2018.06.006.

Robbins, R. K., R. G. Saacke, and P. T. Chandler. 1976. Influence of freeze rate, thaw rate and glycerol level on acrosomal retention and survival of bovine spermatozoa frozen in French straws. J. Anim. Sci. 42:145-154.

Sales, J. N. S., K. A. L. Neves, A. H. Souza, G. A. Crepaldi, R. V. Sala, M. Fosado, E. P. C. Filho, M. de Faria, M. F. S. Filho, and P. S. Baruselli. 2011. Timing of insemination and fertility in dairy and beef cattle receiving timed artificial insemination using sex-sorted sperm. Theriogenology 76:427-435. https://doi.org/10 $.1016 / \mathrm{j}$.theriogenology.2011.02.019.

Shalloo, L., A. Cromie, and N. McHugh. 2014. Effect of fertility on the economics of pasture-based dairy systems. Animal 8(Suppl. 1):222-231. https://doi.org/10.1017/S1751731114000615.

Shannon, P., and R. Vishwanath. 1995. The effect of optimal and suboptimal concentrations of sperm on the fertility of fresh and frozen bovine semen and a theoretical model to explain the fertility differences. Anim. Reprod. Sci. 39:1-10. https://doi.org/10.1016/ 0378-4320(95)01376-B.
Teagasc. 2014. Understanding the economic breeding index (EBI). Accessed Mar. 14, 2019. https://www.teagasc.ie/media/website/ animals/dairy/Understanding_EBI_PTA_BV_Spring_2014.pdf.

Utt, M. D. 2016. Prediction of bull fertility. Anim. Reprod. Sci. 169:37-44. https://doi.org/10.1016/j.anireprosci.2015.12.011.

Vishwanath, R., and J. F. Moreno. 2018. Review: Semen sexing-Current state of the art with emphasis on bovine species. Animal 12(Suppl. 1):s85-s96. https://doi.org/10.1017/ S1751731118000496.

Vishwanath, R., and P. Shannon. 1997. Do sperm cells age? A review of the physiological changes in sperm during storage at ambient temperature. Reprod. Fertil. Dev. 9:321-331. https://doi.org/10 .1071/R96088.

Xu, Z. Z. 2014. Application of liquid semen technology improves conception rate of sex-sorted semen in lactating dairy cows. J. Dairy Sci. 97:7298-7304. https://doi.org/10.3168/jds.2014-8507.

Yang, L., N. López-Villalobos, D. Berry, and T. Parkinson. 2010. Phenotypic relationships between milk protein percentage and reproductive performance in three strains of Holstein Friesian cows in Ireland. Pages 29-32 in Proc. New Zealand Society of Animal Production. New Zealand Society of Animal Production, Palmerston North. 